\title{
An Investigation of the Nurse Practitioner's Knowledge and Self-Efficacy on Expanded Back to Sleep Guidelines and Practice of Providing Anticipatory Guidance: A Descriptive Correlational Study
}

Amy M. Kacho

amkacho@cedarville.edu

Follow this and additional works at: http://digitalcommons.cedarville.edu/nursing theses

Part of the Nursing Commons

\section{Recommended Citation}

Kacho, Amy M., "An Investigation of the Nurse Practitioner's Knowledge and Self-Efficacy on Expanded Back to Sleep Guidelines and Practice of Providing Anticipatory Guidance: A Descriptive Correlational Study" (2015). Master of Science in Nursing Theses. 16.

http://digitalcommons.cedarville.edu/nursing_theses/16 
An Investigation of the Nurse Practitioner's Knowledge and Self-Efficacy on Expanded Back to Sleep Guidelines and Practice of Providing Anticipatory Guidance: A Descriptive Correlational Study

By

Amy Marie Kacho

B.S.N. Wright State University, 2003

2015

Cedarville University 


\begin{abstract}
Significance of the problem: Despite an overall drop in the rate of Sudden Infant Death Syndrome (SIDS) in the United States, equivalent increases of Sudden Unexpected Infant Deaths (SUIDS) have occurred. SUIDS are infant deaths from suffocation, strangulation or other factors related to the infants sleeping environment; in 2011 the American Academy of Pediatrics (AAP) expanded the Back to Sleep recommendations to include SUIDS causes of death.
\end{abstract}

Relevant to nurses: Nurse Practitioners (NPs) play a key role in implementing Back to Sleep recommendations, yet there is a very little literature exploring the frequency and consistency with which NPs provide educational interventions among parents and infant care providers.

Purpose statement: Therefore, the purpose of this study is to assess the NPs knowledge and self-efficacy related to recommendations for a safe infant sleeping environment and whether NPs are providing anticipatory guidance regarding expanded AAP recommendations.

Methodology: This descriptive correlational study includes data collected by cross sectional survey and is guided by the transtheoretical model. 
An Investigation of the Nurse Practitioner's Knowledge and Self-Efficacy on Expanded Back to Sleep Guidelines and Practice of Providing Anticipatory Guidance: A Descriptive Correlational Study

\section{Chapter 1}

\section{Introduction}

According to the Centers for Disease Control and Prevention (CDC), 4000 infants less than 1 year of age die each year suddenly and unexpectedly in the United States without an apparent cause. Over half of these Sudden Unexpected Infant Deaths (SUIDs) are due to Sudden Infant Death Syndrome (SIDS). SIDS is a sudden death of an infant which is unexplained despite a complete autopsy, examination of the death scene and review of the clinical history (Sudden Infant Death Syndrome (SIDS), 2013). SIDS is the leading cause of death among infants 1-12 months of age. It is commonly referred to as "crib death" because it is associated with the time and environment in which the infant is sleeping (Sudden Infant Death Syndrome: Medline, 2013). The three most frequently reported causes of SUIDs are SIDS, accidental suffocation and strangulation in bed, and cause unknown (Sudden Unexpected Infant Death (SUID), 2014).

In 1992, the American Academy of Pediatrics (AAP) recommended placing babies on their backs while sleeping. Additionally, the National Institute of Child Health and Human Development (NICHD) began the Back to Sleep Campaign in 1994 as an approach to educate parents, caregivers, and health care providers about ways to reduce the risk for SIDS (Safe to Sleep Public Education Campaign, 2013). The campaign focused on advocating placing infants on their backs during sleep and other risk- reduction strategies. Between 1992 and 1999, growing public awareness and successful intervention strategies of this campaign led to a decrease in the overall SIDS rates in the US by more than $50 \%$, and frequencies of back sleeping more than doubled (Progress in Reducing SIDS, 2013). In contrast, while SIDS rates were dropping and stabilizing, a corresponding increase of SUIDS (such as accidental suffocation or strangulation in bed) occurred (Progress in Reducing SIDS, 2013). 
In 2011, the AAP expanded the Back to Sleep recommendations to address additional causes of sleep-related deaths such as suffocation, asphyxia, and entrapment (AAPTFSIDS, 2011). This document contains 18 recommendations for healthy infants without medical concerns. Infants with prior medical concerns may require additional considerations (Meadows-Oliver \& Hendrie, 2013).

In accordance with injury prevention and anticipatory guidance, reducing infant deaths from SIDS and SUIDS is a top priority for Nurse Practitioners. As a primary care provider, nurse practitioners are in an ideal position to promote these new recommendations, educate parents and caregivers about safe sleep environments, and influence sleep behavior of parents with their infants while promoting evidence-based recommendations. Expanded guidelines from the AAP advises health care professionals, staff in the NICU and newborn nurseries, and child care providers to endorse and model SIDS risk-reduction recommendations (Meadows-Oliver \& Hendrie, 2013). Furthermore, primary care-based interventions, particularly those addressing caregiver concerns and misconceptions about safe sleep recommendations, can be valuable in improving adherence with recommendations among their patients (Moon, 2011). The AAP recommends primary care providers develop quality improvement initiatives to foster adherence with the expanded recommendations (Moon, 2011). With improved modeling and education of the SIDS risk-reduction recommendations by health care professionals; advertisements following safe sleep guidelines; expansion of national campaigns; and continued research and surveillance on risk factors, causes, and pathophysiological mechanisms of SIDS and SUIDS; there can be more public awareness and therefore, an overall reduction in the risk of both SIDS and other sleep-related infant deaths (MeadowsOliver \& Hendrie, 2013; Moon, 2011).

\section{Literature review}

A literature review was conducted using One Search. Peer reviewed articles were included since 2011. Key search words included sudden infant death prevention, 2011 expanded back to sleep 
guidelines, health promotion, and injury prevention in children. After the initial search, an additional search was done, including articles over the last 15 years.

A study by Weber, Risdon, Ashorth, Malone \& Sebire (2012) found 59\% of SUIDS was associated with sharing a sleeping surface with one or both parents. Additionally, a study by Schnitzer, Covington \& Dykstra (2012) found 70\% of SUIDS were associated with infants sleeping on a surface not intended for infant sleep. Of these, $64 \%$ of SUIDS infants were sharing the sleep surface with a person or animal and almost half were sharing the sleep surface with an adult. (Covington \& Dykstra, 2012).

Since the 2011 expansion of recommendations for a safe infant sleeping environments, studies have been done assessing the knowledge and safe sleep practices of NICU and nursery workers (Fowler, Evans, Etchegarary, Ottenbacher \& Arnold, 2013), and the hospital setting (Masson, Ahlers-Schmidt\& Schunm, 2013); the knowledge, opinions and practices regarding infant sleep position among parents (Chung, 2012); and the knowledge and practices of safe sleep recommendations and SIDS risk reduction guidelines among child care providers (Clark \& Auten, 2011). Conversely, there is very little research examining whether primary care providers, particularly nurse practitioners, are educating parents and infant care givers on the expanded recommendations. One study in Turkey examined the knowledge and attitude of parents and health professionals about SIDS using telephone and face to face interviews (Ykilkan, Hulya, Cakir \& Ersu, 2011). Another study sent cross-sectional surveys to pediatricians, obstetricians and family practitioners examining knowledge of SIDS and whether physicians are discussing how to reduce the risk of SIDS with parents (Enron, Dygert et al, 2011). Finally, Moon, Gingras \& Erwin (2002) surveyed a random sample of physicians to determine knowledge, beliefs and practices regarding SIDS and SIDS risk reduction. The studies conducted by Moon et al (2002) and Enron et al (2011) both had low response rates and focused on physicians exclusively. Additionally, they were both completed prior to the 2011 expanded guidelines. However, despite the low response rates, results from both studies were comparable and concluded many physicians are not discussing how to reduce the risk of SIDS with parents. Additionally, both studies had respondents from large geographical 
areas, providing a more accurate representation of the target population. The study by Ykilkan et al (2011), conducted prior to the 2011 expanded guidelines, focused on knowledge of mothers and generalized health professionals including doctors, nurses and midwives. There is a gap in the literature related to assessing knowledge and educational interventions among primary care providers regarding the 2011 expanded recommendations for a safe sleeping environment. Additionally, no studies have been done studying the knowledge and educational interventions among nurse practitioners, exclusively.

\section{Review of Injury Prevention Literature}

Discussing a safe sleeping environment is an important part of anticipatory guidance in newborns and infants. Studies demonstrated pediatric primary care providers play a vital role in preventing unintentional injuries and death in children, yet injury and death prevention counseling is not routinely integrated within their practices (Jennessen, Denning et al, 2012; Barkin 1999). For health care providers to educate parents and caregivers about injury prevention, they themselves must be fully knowledgeable and confident about risks and reduction strategies. Recently, Jennissen, Denning, et al (2012) administered an electronic survey to 218 primary care providers. Even though more than $60 \%$ of respondents believed anticipatory guidance was important to provide to patients and their families, less than $12 \%$ routinely provided All-terrain vehicle (ATV) safety counseling during regular pediatric exams (Jennissen, Denning et al, 2012). Another study by Barkin (1999) revealed 2/3 of primary care providers were unaware drowning occurred more frequently than toxic ingestions and firearm injuries.

Additionally, only $1 / 3$ of providers counseled on drowning prevention. Therefore, knowledge deficit may be a potential barrier for implementing injury and death preventative counseling (Barkin, 1999).

Purpose of the research: The purpose of this study is to assess the NPs knowledge and self-efficacy related to recommendations for a safe infant sleeping environment and whether NPs are providing anticipatory guidance regarding expanded AAP recommendations. 


\section{Chapter 2}

\section{Theoretical framework}

The transtheoretical model was used to guide this study. This model was developed by Prochaska between 1977 and 1997 (Prochaska \& Velicer, 1997). The transtheoretical model uses different theories of intervention to integrate processes and principles of change (Prochaska \& Velicer, 1997). It was initially applied to smoking cessation and then later applied to a broad range of health behaviors including substance abuse, depression, obesity and HIV/AIDS prevention (Prochaska \& Velicer, 1997). It consists

of four core constructs including stages of change, process of change, decisional balance and self-efficacy (Prochaska \& Velicer, 1997). The stages of change include a period of time as well as what needs to be accomplished to move into the next stage (Norcross, Krebs \& Prochaska, 2010). The stages include precontemplation, contemplation, preparation, action, maintenance.

\section{Conceptual definition of self- efficacy}

Self-Efficacy is described as one's confidence in their ability to do the behavior (Norcross, Krebs \& Prochaska, 2010).

(Confidence in ability to educate parents and infant caregivers regarding the 2011 expanded recommendations for a safe sleeping environment)

Operational definition of self-efficacy- measured by questionnaire to assess confidence in ability to educate parents and infant caregivers regarding the 2011 expanded recommendations for a safe sleeping environment, developed by this researcher. 


\section{Conceptual definition of knowledge}

Knowledge is defined as "essential content or body of information for a discipline that is acquired through traditions, authority, borrowing, trial and error, personal experience, role-modeling and mentorship, intuition, reasoning, and research” (Burns \& Grove, 2009)

Operational definition of knowledge-measured by questionnaire regarding 2011 expanded recommendations for a safe sleeping environment, developed by this researcher.

\section{Summary of 2011 AAP Recommendations}

1. The recommended position for infant sleep remains on their backs (Moon, 2011).

2. A safety-approved crib with a firm mattress and tight-fitting sheet should be used (Moon, 2011).

3. No wedges or positioning devices should be used, and soft objects and loose bedding should be kept out of the crib (Moon, 2011).

4. An infant sleep surface be in close proximity to the parent's bed to foster comforting, feeding and monitoring (Moon, 2011). (This "room sharing" has been found to reduce SIDS).

5. No one should share sleep surfaces with an infant (Moon, 2011). ("bed sharing" in which the infant sleeps on the same surface, such as a bed, couch or chair with another person, increases risk of suffocation and other sleep-related causes of death (Moon, 2011).

6. Women are encouraged to receive regular prenatal care while pregnant and avoid smoking, smoke exposure; alcohol and illicit drug use during pregnancy and after birth (Moon, 2011).

7. Infant immunization, in accordance with recommendations from the AAP and the CDC, is further advocated (Meadows-Oliver \& Hendrie, 2013).

8. Other recommendations from expanded guidelines include breastfeeding, use of a pacifier at naptime and bedtime, avoiding overheating, avoiding use of home cardiorespiratory monitors, and using supervised and awake tummy time to facilitate development (Meadows-Oliver \& Hendrie, 2013). 


\section{Conceptual definition of the stages of change}

Stages of change represents when people change (Norcross, Krebs, Prochaska, 2010).

- Precontemplation (Not Ready)-People are not intending to take action in the foreseeable future (within 6 months), and can be unaware their behavior is problematic (Norcross, Krebs \& Prochaska, 2010).

(I do not educate about the AAP's expanded recommendations for a safe infant sleeping environment and I do not intend to start)

- Contemplation (Getting Ready)-People are starting to recognize their behavior is problematic and start to look at the possibility of changing their behavior but have not made the commitment to take action (Norcross, Krebs \& Prochaska, 2010).

(I do not educate about the AAP's expanded recommendations for a safe infant sleeping environment, but I am thinking about starting)

- Preparation (Ready)-People are intending to change their behavior in the immediate future, and may begin taking small steps (Norcross, Krebs \& Prochaska, 2010).

(I do not educate about the AAP's expanded recommendations for a safe infant sleeping environment, but I have ordered updated educational materials to implement in my teaching practice beginning sometime within the next 6 months)

- Action - People have made specific overt behavior modifications or in acquiring new healthy behaviors (Norcross, Krebs \& Prochaska, 2010). 
(I have been educating about the AAP's expanded recommendations for a safe infant sleeping environment for less than 6 months)

- Maintenance - People have been able to continue with the behavior modifications for a while and are working to prevent relapse (Norcross, Krebs \& Prochaska, 2010).

(I have been educating about the AAP's expanded recommendations for a safe infant sleeping environment longer than 6 months and I plan to continue)

Operational definition of the stages of change -A questionnaire examining the stages of change for SUID was developed by this researcher.

\section{Stage of change}

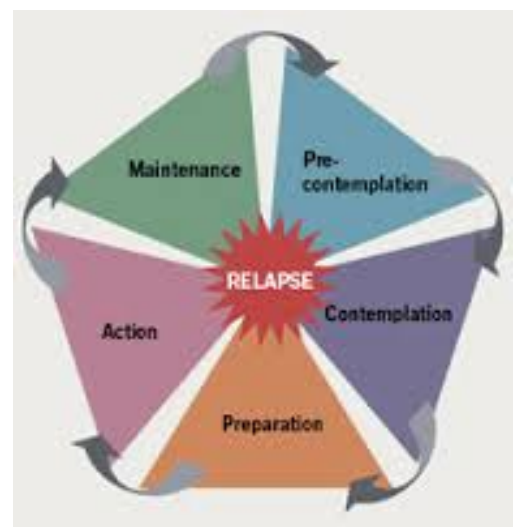

(O'Brien, Lesley, Morag Throw, and Danny Raffert, 2009).

\section{Conceptual definition of the process of change}

The process of change represents the progress through the stages of change and the explicit and concealed activities the individuals engage in when they are modifying their behavior. This may include cognitive, affective and evaluative processes (Norcross, Krebs \& Prochaska, 2010). (This study did not focus on the process of change, but may be relevant for further studies regarding this subject). 
As previously mentioned, there is very little research examining whether primary care providers, particularly nurse practitioners, are educating parents and infant care givers on AAP's expanded recommendations for safe sleeping. Additionally, there is no literature examining 2011 AAP guidelines implementation using the transtheoretical model.

\section{Methods (Chapter 3)}

\section{Subjects}

This researcher contacted the Ohio Board of Nursing for email access to potential study participants. The researcher was directed to the Public Information Request Tracking (PIRT) team from Ohio's Office of Information Technology Enterprise Computing which provides licensee data for the state of Ohio to the public through computerized databases. Inclusion criteria for this study included certified nurse practitioners. Exclusion criteria included anyone who is not a certified nurse practitioner or is unable to complete the survey. Based on inclusion criteria, the researcher randomly selected 2000 potential participants from a database of over 8000 nurse practitioners. Subjects were asked to completed questionnaires electronically. IRB approval was obtained from Cedarville University.

\section{Demographic variables}

Demographic variables included in the survey included age, ethnicity, gender, board certification status, practitioner type, practice specialty, and years worked in practice setting (to determine if respondents represent an accurate sample nationwide).

\section{Design}

This descriptive correlational study was designed to determine if there is a relationship among variables (assess the NPs knowledge and self-efficacy related to recommendations for a safe infant sleeping environment and whether NPs are providing anticipatory guidance regarding expanded AAP 
recommendations). This researcher asked subjects to complete questionnaires that were developed by this researcher. Variables were not manipulated and there were no interventions for this study.

\section{Strengths and weaknesses}

Strengths of this study included little to no expense; questionnaires requiring minimal time to complete; no risk to human subjects; researcher had support of academic committees, institutional support and personal support, and this was an exempt study. Participants completed the questionnaire online via a link through Qualtrics to promote data accuracy verification, selective data extraction and analysis. This descriptive study addresses gaps in the literature by exploring knowledge and educational interventions among nurse practitioners regarding the 2011 expanded recommendations for a safe sleeping environment. This study will provide a foundation to raise awareness about the 2011 update in the recommendations.

Weaknesses of this study included the questionaire being developed by the researcher. Therefore, only face validity and content validity were established. Other weaknesses include external factors such as mood and strong personal feelings of subjects during time questionnaires were completed.

Additionally, only collecting data from subjects at one sitting may promote external factors, thereby reducing accuracy in responses. Furthermore, distributing questionnaires electronically diminishes environmental control in which the subjects complete questionnaires. There is also possibility of the Hawthorne effect occurring in which subjects change their responses simply because they know they are subjects in a study (Burns \& Grove, 2009).

\section{Measurement tools and data collection}

Measurement tools included a demographic form to collect information regarding age, ethnicity, gender, board certification status, practitioner type, practice specialty, and years worked in practice setting. Furthermore, a questionnaire examining stages of change for SUID, self-efficacy and knowledge of nurse practitioners regarding the 2011 expanded recommendations for a safe sleeping environment was 
obtained. Section one consisted of one multiple choice question to assess stages of change. Section two consisted of one select all that apply question to assess self-efficacy. Section three consisted of ten yes or no questions and one select all that apply question to assess knowledge of the nurse practitioners regarding the 2011 expanded recommendations for a safe sleeping environment. For educational purposes, a screen with 2011 expanded recommendations displayed at the end of the survey. For the purpose of this study, process of change was not measured.

Reliability and validity was evaluated after questionnaire development. Experts examined the questionnaire for content validity and face validity. The questionnaire was trialed among Cedarville University nurse practitioners and faculty to look at consistency and comparability. The panel consisted of three experts: (1) A doctor of philosophy who serves as a Professor of Nursing at Cedarville University (2) A pediatric nurse practitioner who serves as Assistant Professor of Nursing at Cedarville University and (3) A doctor of nursing practice who serves as the Interim Dean at Cedarville University. The questionnaire was designed to not take longer than 5 minutes to complete. It was revised based on feedback from the panel. This descriptive study included data collected by cross sectional survey. A random sample of 2000 nurse practitioners were invited to participate via email. This provided a sample that is a more accurate representation of the population. The email gave brief information about the study and explained the following:

1. This survey is completely voluntary.

2. If you choose not to complete this survey, you will not be affected in any way.

3. This survey is completely confidential by clicking on the link.

4. All results will remain anonymous.

Participants completed the questionnaire online via a link through Qualtrics to promote data accuracy verification, selective data extraction and analysis. There was no cost incurred with this study; university owned software was utilized. The email was sent out to participants on March 5, 2015. The link 
remained active until March 12, 2015. An appreciation message was sent to participants upon completion of the questionnaire provided by the Qualtric's Survey Program. Data analysis was conducted immediately following data collection.

\section{Data analysis}

This researcher examined correlation between variables and demographics and specific correlation of knowledge and self-efficacy with frequency and consistency with which NPs provide educational interventions among parents and infant caregivers. Strength of the relationship between variables varied from -1 (perfect negative correlation) to +1 perfect positive correlation, with 0 indicating no relationship. Data Analysis was conducted using PSPP with the assistance of Dr. Sharon Christman Ph.D., RN, FAHA, Director of Research and Professor of Nursing at Cedarville University. Descriptive statistics (means, standard deviation, frequency, percentage and Pearson correlations) were considered for the purpose of this study.

\section{Ethical considerations}

IRB approval was obtained from Cedarville University. This was an exempt study. Privacy and confidentiality was maintained and protected regarding subjects and data collected. Implied consent was obtained by voluntary completion of the questionnaire. There was no risk for human subject harm, anticipated effects, temporary discomfort or risk of permanent damage. Subjects were asked to complete the survey and had the right to refuse. 


\section{Thesis committee}

\section{Chair of committee}

Angelia Mickle, DNP, FNP-C, CEN

Interim Dean, Assistant Professor of Nursing

Cedarville University

School of Nursing

\section{Committee members}

Kim Higginbotham, M.S.N., RN, APRN, CPNP

Assistant Professor of Nursing

Cedarville University

School of Nursing

\section{Results (Chapter 4)}

There is very little research examining whether primary care providers, particularly nurse practitioners, are educating parents and infant care givers on AAP's expanded recommendations for safe sleeping. Additionally, there is no literature examining 2011 AAP guidelines implementation using the transtheoretical model. Therefore, the purpose of this study is to assess the NPs knowledge and selfefficacy related to recommendations for a safe infant sleeping environment and whether NPs are providing anticipatory guidance regarding expanded AAP recommendations. An electronic survey was sent to 2000 participants via the Qualtrics Survey Program in March 2015. A total of N=171 completed and returned the survey. The overall response rate was $8.5 \%$. 


\section{Demographic characteristics}

Demographic characteristics are presented in the Demographic Table. Of the 165 participants who completed Demographic data, the majority were white or non-Hispanic (92\%, $n=153)$, between the ages of 36-45 (28.3\%, $\mathrm{n}=47)$, Family Nurse Practitioners $(51.2 \%, \mathrm{n}=85)$, working in family practice (26.9\%, $\mathrm{n}=46)$, and working in practice for $0-5$ years in practice $(47.9 \%, \mathrm{n}=79)$. Adult Nurse Practitioners and those who did not complete the survey were excluded from the data analysis $(n=46)$. Family Nurse Practitioners, Pediatric Nurse Practitioners, Women's Health Nurse Practitioners and Acute Care Nurse Practitioners who completed the survey were included in the data analysis $(n=125)$. However, there was no significant difference in the demographic data between those included and excluded.

\begin{tabular}{|l|l|l|}
\hline Variables & N & Percentages \\
\hline Race/Ethnicity & & \\
\hline$\underline{\text { White }}$ & 114 & $\underline{91.2 \%}$ \\
\hline$\underline{\text { Black }}$ & 7 & $5.6 \%$ \\
\hline$\underline{\text { Am. Indian }}$ & 1 & $0.8 \%$ \\
\hline$\underline{\text { Asian }}$ & 1 & $0.8 \%$ \\
\hline$\underline{\text { Hispanic }}$ & 1 & $0.8 \%$ \\
\hline Other & 1 & $0.8 \%$ \\
\hline Total & 125 & $100 \%$ \\
\hline
\end{tabular}




\begin{tabular}{|c|c|c|}
\hline Years wo & & \\
\hline$\underline{0-5}$ & 61 & $48.8 \%$ \\
\hline $6-10$ & 24 & $19.2 \%$ \\
\hline 11-15 & 19 & $15.2 \%$ \\
\hline$\underline{16-20}$ & 9 & $7.2 \%$ \\
\hline$\underline{20+}$ & 12 & $9.6 \%$ \\
\hline Practitio & & \\
\hline FNP & 73 & $58.4 \%$ \\
\hline PNP & 27 & 21.6 \\
\hline WHNP & 4 & $3.2 \%$ \\
\hline$\underline{N N P}$ & 13 & $10.4 \%$ \\
\hline ACNP & 8 & $6.4 \%$ \\
\hline Total & 125 & $100 \%$ \\
\hline
\end{tabular}

\section{Knowledge and practitioner type}

There was a significant difference in the knowledge level of the expanded AAP recommendations between the practitioner types $(\mathrm{p}<0.0001)$. For example, $100 \%$ of Women's Health Nurse Practitioners $(n=4)$ and Neonatal Nurse Practitioners $(n=13)$ stated they were aware of the expanded AAP 
recommendations. Additionally, $92 \%$ of Pediatric Nurse Practitioners $(n=25)$ were aware. On the other hand, only $58 \%$ of Family Nurse Practitioners $(n=43)$ and $37 \%$ of Acute Care Nurse Practitioners $(n=3)$ were aware of the expanded AAP recommendations. Additionally, there was a significant difference in practitioner type and the ability to list five of the expanded recommendations $(\mathrm{p}<0.001)$. All of the Neonatal Nurse Practitioners $(100 \%, \mathrm{n}=13)$, and most of the Pediatric Nurse Practitioners $(81 \%, \mathrm{n}=22)$ and Women's Health Nurse Practitioners $(75 \%, \mathrm{n}=3)$ were able to list 5 recommendations. On the other hand, only 54\% $(n=40)$ of the Family Nurse Practitioners and 33\% $(n=2)$ of the Acute Care Nurse Practitioners were able to list 5 recommendations. Lastly, there was a significant difference in the nurse practitioner type and whether or not they had been sufficiently educated on the expanded recommendations $(\mathrm{p}<0.001)$. All of the Neonatal Nurse Practitioners $(100 \%, n=13)$, and most of the Pediatric Nurse Practitioners $(88 \%, n=24)$, and Women's Health Nurse Practitioners $(75 \%, n=3)$ reported being sufficiently educated on the expanded recommendations. Conversely, only $51 \%(n=37)$ of the Family Nurse Practitioners and 38\% (n=3) of the Acute Care Nurse Practitioners reported being sufficiently educated on the expanded recommendations.

\begin{tabular}{|l|l|l|l|l|}
\hline & $\begin{array}{l}\text { Knowledge } \\
\text { I am aware of } \\
\text { guidelines } \\
\text { Yes }\end{array}$ & $\begin{array}{l}\text { Knowledge } \\
\text { I am aware of } \\
\text { guidelines } \\
\text { NO }\end{array}$ \\
\hline $\begin{array}{l}\text { Practitioner } \\
\text { Type }\end{array}$ & N & $\%$ & N & $\%$ \\
\hline$\underline{\text { FNP }}$ & 43 & $58 \%$ & 30 & $42 \%$ \\
\hline $\boldsymbol{P N P}$ & 25 & $\mathbf{9 2 \%}$ & 2 & $8 \%$ \\
\hline WHNP & 4 & $\mathbf{1 0 0 \%}$ & 0 & $0 \%$ \\
\hline
\end{tabular}




\begin{tabular}{|l|l|l|l|l|}
\hline $\mathbf{N N P}$ & 13 & $100 \%$ & 0 & $0 \%$ \\
\hline$\underline{A C N P}$ & 3 & $37 \%$ & 5 & $63 \%$ \\
\hline
\end{tabular}

\section{Knowledge and age}

There was no significant difference $(\mathrm{p}>0.334)$ between the age (years) of the nurse practitioners and whether they were aware of the expanded AAP recommendations. However, $84 \%(n=31)$ of nurse practitioners between the ages of 25-35 reported they had been sufficiently educated on the 2011 expanded recommendations. While on the other hand, $51 \%(n=24)$ between the ages of $36-45,59 \%$ $(n=18)$ between the ages of $46-55$, and $56 \%(n=15)$ of nurse practitioners 56 and older reported they had been sufficiently educated on the 2011 expanded recommendations $(\mathrm{p}<0.038)$.

\begin{tabular}{|l|l|l|}
\hline Variable & $\begin{array}{l}\text { I have been educated } \\
\text { about 2011 } \\
\text { recommedations } \\
\text { YES }\end{array}$ & $\begin{array}{l}\text { I have been educated } \\
\text { about 2011 } \\
\text { recommedations } \\
\text { NO }\end{array}$ \\
\hline Age & n & n \\
\hline$\underline{\mathbf{2 5 - 3 5}}$ & 32 & $\underline{6}$ \\
\hline$\underline{\mathbf{3 6 - 4 5}}$ & 19 & 18 \\
\hline$\underline{\mathbf{4 6 - 5 5}}$ & 16 & 11 \\
\hline$\underline{\mathbf{5 6 +}}$ & $\mathbf{1 3}$ & $\underline{10}$ \\
\hline
\end{tabular}




\section{Knowledge and stage of change}

The majority $(89 \%, \mathrm{n}=75)$ of the nurse practitioners who were aware of the expanded recommendations reported they had been educating parents and infant caregivers about the recommendations for a safe infant sleeping environment. However, only $10 \%(n=9)$ of the nurse practitioners stated they were not aware of the guidelines reported they had been educating parents and infant caregivers about the recommendations for a safe infant sleeping environment $(\mathrm{p}<0.001)$.

\begin{tabular}{|l|l|l|}
\hline & $\begin{array}{l}\text { Knowledge } \\
\text { I am aware of } \\
\text { guidelines } \\
\text { Yes }\end{array}$ & $\begin{array}{l}\text { Knowledge } \\
\text { I am aware of } \\
\text { guidelines } \\
\text { No }\end{array}$ \\
\hline Stage of change & $\mathbf{n}$ & $\mathbf{n}$ \\
\hline$\underline{\text { Precontemplation }}$ & 11 & $\mathbf{1 6}$ \\
\hline$\underline{\text { Contemplation }}$ & 1 & 9 \\
\hline Preparation & 0 & 2 \\
\hline$\underline{\text { Action }}$ & 2 & 1 \\
\hline Maintainance & 73 & 8 \\
\hline
\end{tabular}

\section{Stage of change and practitioner type}

100\% ( $n=27)$ of Pediatric Nurse Practitioners, $100 \%(n=13)$ Neonatal Nurse Practitioners and 75\% $(\mathrm{n}=3)$ of Women's Health Nurse Practitioners reported they had been educating parents and infant caregivers about the AAP's expanded recommendations for a safe infant sleeping environment. On the other hand, only 56\% (n=40) of Family Nurse Practitioners and 12\% (n=1) of Acute Care Nurse Practitioners reported they had been educating parents and infant caregivers about the AAP's expanded recommendations for a safe infant sleeping environment $(\mathrm{p}<0.001)$. 


\begin{tabular}{|c|c|c|c|c|}
\hline \multirow[t]{2}{*}{$\begin{array}{l}\text { Practitioner } \\
\text { Type }\end{array}$} & \multicolumn{2}{|c|}{$\begin{array}{l}\text { SOC } \\
\text { Precontemplation/ } \\
\text { Contemplation/ } \\
\text { Preparation } \\
\text { (Not educating) }\end{array}$} & \multicolumn{2}{|c|}{$\begin{array}{l}\text { SOC } \\
\text { Action/ } \\
\text { Maintainance } \\
\text { (educating) }\end{array}$} \\
\hline & $\mathbf{n}$ & $\%$ & $\mathrm{n}$ & $\%$ \\
\hline$\underline{F N P}$ & 31 & $44 \%$ & 40 & $56 \%$ \\
\hline$\underline{P N P}$ & 0 & $0 \%$ & 27 & $100 \%$ \\
\hline WHNP & 1 & $25 \%$ & 3 & $75 \%$ \\
\hline$\underline{N N P}$ & 0 & $0 \%$ & 13 & $100 \%$ \\
\hline$A C N P$ & 7 & $88 \%$ & 1 & $12 \%$ \\
\hline
\end{tabular}

\section{Stage of change and self-efficacy}

Sixty-four percent $(n=54)$ of the nurse practitioners who educate parents and infant caregivers about the AAP's expanded recommendations for a safe infant sleeping environment report they felt confident about educating. On the other hand, 34\% (n=38) who do not educate parents and infant caregivers about the AAP's expanded recommendations for a safe infant sleeping environment report they felt confident about educating $(\mathrm{p}<0.005)$. 


\begin{tabular}{|l|l|l|}
\hline & $\begin{array}{l}\text { I educated and felt } \\
\text { confident }\end{array}$ & $\begin{array}{l}\text { I educated and felt } \\
\text { confident }\end{array}$ \\
\hline O(No) & N (Yes) \\
\hline SOC & N & N \\
\hline$\underline{\text { Precontemplation }}$ & 20 & 6 \\
\hline$\underline{\text { Contemplation }}$ & 5 & 5 \\
\hline$\underline{\text { Preparation }}$ & 1 & 1 \\
\hline$\underline{\text { Action }}$ & 2 & 1 \\
\hline$\underline{\text { Maintainance }}$ & 28 & 53 \\
\hline
\end{tabular}

\section{Demographics and self-efficacy}

There was no significant difference in the nurse practitioner type and feeling confident $(p>0.237)$, empowered ( $p>0.121)$, encouraged $(p>0.468)$, discouraged $(p>0.423)$, or nervous/anxious $(p>0.833)$ while educating educate parents and infant caregivers about the AAP's expanded recommendations for a safe infant sleeping environment. Furthermore, there was no significant difference in the nurse practitioner age and feeling confident $(p>0.174)$, empowered $(p>0.444)$, encouraged $(p>0.444)$, discouraged ( $p>0.422$ ), or nervous/anxious ( $p>0.307$ ) while educating. Lastly, there was no significant difference in the nurse practitioner's years worked in practice setting and feeling confident $(\mathrm{p}>0.306)$, empowered $(p>0.106)$, encouraged $(p>0.784)$, discouraged $(p>0.785)$, or nervous/anxious $(p>0.759)$ while educating. 


\section{Discussion}

While the Back to Sleep campaign has been successful in decreasing the rate of SIDS in the United States, equivalent increases of infant deaths from suffocation, strangulation or other factors related to the infant's sleeping environment have occurred. In 2011, the AAP expanded the Back to Sleep recommendations to include these SUIDS causes of death. Existing data demonstrates the advice of the infant's health care provider is most influential in determining the infant's sleep position as well as other decisions related to the infant's sleep environment. This survey demonstrates a significant number of nurse practitioners are not even aware of the AAP's 2011 expanded recommendations. This survey demonstrates Women's Health Nurse Practitioners (100\%), Neonatal Nurse Practitioners (100\%) and Pediatric Nurse Practitioners (88\%) are more aware of the updated AAP recommendations compared to Family Nurse Practitioners (51\%) and Acute Care Nurse Practitioners (38\%). Additionally, the survey demonstrates a significant number of nurse practitioners had not been educated about the updated guidelines. All of the Neonatal Nurse Practitioners (100\%) and most of the Pediatric Nurse Practitioners (88\%) and Women's Health Nurse Practitioners (75\%) reported being sufficiently educated about the expanded recommendations, but only $51 \%$ of the Family Nurse Practitioners and $38 \%$ of the Acute Care Nurse Practitioners reported being educated on the expanded recommendations. Many nurse practitioners continue to be unaware of the expanded recommendations that focus on modifiable risk factors related to the infant's environment; this knowledge deficit causes great concern. It may be clinically relevant that a higher percentage of younger nurse practitioners (84\%) report they have been educated on the recommendations compared to only $56 \%$ of older nurse practitioners. It is crucial that outreach and educational efforts be made to all nurse practitioners who work with infants regardless of the number of infants seen on a regular basis. Nurse Practitioners who are more knowledgeable appear to be more likely to provide anticipatory guidance. This survey showed the majority (89\%) of the nurse practitioners who were aware of the guidelines educated parents and infant caregivers about the recommendations, while only $10 \%$ of the nurse practitioners who were not aware of the guidelines were providing anticipatory 
guidance regarding to the expanded AAP recommendations. Specifically, Pediatric Nurse Practitioners (100\%), Neonatal Nurse Practitioners (100\%) and Women's Health Nurse Practitioners (75\%) were more likely to provide anticipatory guidance related to the AAP's expanded recommendations for a safe infant sleeping environment compared to Family Nurse Practitioners (56\%) and Acute Care Nurse Practitioners (12\%). It also appears evident that the nurse practitioner may be more likely to provide anticipatory guidance when they feel confident about their ability to do so. The survey demonstrated $64 \%$ of the nurse practitioners who educate parents and infant caregivers about the AAP's expanded recommendations for a safe infant sleeping environment report they felt confident while educating. On the other hand, 34\% who do not educate parents and infant caregivers about the AAP's expanded recommendations for a safe infant sleeping environment report they felt confident while educating. More research is needed to determine the relationship between knowledge, self-efficacy and providing anticipatory guidance.

Hopefully, this survey helped alert nurse practitioners of the modifiable risk factors associated with an infant's sleeping environment including sleep position, smoke exposure, overheating, soft/loose bedding and other updated recommendations as guided by the AAP. If all modifiable risk factors are removed, the incidence of SIDS will likely continue to decline. Since Nurse Practitioners and other health care professionals are critically important to providing anticipatory guidance to parents and infant caregivers, it is crucial nurse practitioners who care for infants become aware of these expanded guidelines. Offering outreach and education seminars are crucial, so nurse practitioners can promote safe sleep practices for their patients. 


\section{References}

American Academy of Pediatrics Task Force on Sudden Infant Death Syndrome (AAPTFSIDS). (2011).

SIDS and other sleep-related infant deaths: Expansion of recommendations for a safe infant sleeping environment. Pediatrics, 128, 1030-1039.

Barkin, S. (1999). Sink or Swim-Clinicians Don't Often Counsel on Drowning Prevention. Pediatrics, 104(5), 1217.

http://0search.ebscohost.com.library.cedarville.edu/login.aspx $?$ direct $=$ true $\& d b=f 5 h \& A N=2482949 \&$ site $=$ eds- live

Burns, N., \& Grove, S. K. (2009). The practice of nursing research: appraisal, synthesis, and generation of evidence (6th ed.). St. Louis, Mo.: Saunders/Elsevier.

Chung-Park, M. S. (2012). Knowledge, Opinions, and Practices of Infant Sleep Position among Parents. Military Medicine, 177(2), 235-239

Clark, A., \& Auten, C. (2011). Assessing Child Care Providers' SIDS Practices and Website Educational Material Use. Relational Child \& Youth Care Practice, 24(3), 33-39.

Eron, N. B., Dygert, K. M., Squillace, C., Webster, N. J., Andrianos, A., Crockett, E. G., \& Consenstein, L. (2011). The Physician's Role in Reducing SIDS. Health Promotion Practice, 12(3), 370-378. doi:10.1177/1524839909341033

Fowler, A. J., Evans, P. W., Etchegaray, J. M., Ottenbacher, A., \& Arnold, C. (2013). Safe Sleep Practices and Sudden Infant Death Syndrome Risk Reduction: NICU and Well-Baby Nursery 
Graduates. Clinical Pediatrics, 52(11), 1044-1053. doi:10.1177/0009922813506038

Jennissen, C., Denning, G., Sweat, S., Harland, K., \& Buresh, C. (2012). All-Terrain Vehicle Injury

Prevention: Healthcare Providers' Knowledge, Attitudes, and the Anticipatory Guidance They

Provide. Journal Of Community Health, 37(5), 968-975. http://0-

$\underline{\text { search.ebscohost.com.library.cedarville.edu/login.aspx?direct }=\text { true } \& d b=e f t \& A N=79722062 \& \text { site }=e d s-}$

$\underline{\text { live }}$

Mason, B., Ahlers-Schmidt, C. R., \& Schunn, C. (2013). Improving Safe Sleep Environments for Well

Newborns in the Hospital Setting. Clinical Pediatrics, 52(10), 969-975.

doi:10.1177/0009922813495954

Meadows-Oliver, M., \& Hendrie, J. (2013). Expanded Back to Sleep Guidelines. Pediatric Nursing, 39(1), 40-49.

Moon, R., Gingras, J., \& Erwin, R. (2002). Physician beliefs and practices regarding SIDS and SIDS risk reduction. Clinical Pediatrics, 41(6), 391-395.

Moon, R. (2011). SIDS and other sleep-related infant deaths: expansion of recommendations for a safe infant sleeping environment. Pediatrics, 128(5), e1341-e1367. doi:10.1542/peds.2011-2285

Norcross, J., Krebs, P., \& Prochaska, J. (2011). Stages of Change. Journal of Clinical Psychology, 67(2), 143-154.

O'Brien, Lesley, Morag Throw, and Danny Raffert, 2009). "Predicting adherence to phase III cardiac rehabilitation: should we be more optimistic?." The British Journal of Cardiology Predicting 
adherence to phase III cardiac rehabilitation should we be more optimistic Comments. N.p., 1 Sept.

2009. Web. 4 Apr. 2014. <http://bjcardio.co.uk/2009/09/predicting-adherence-to-phase-iii-cardiac-

rehabilitation-should-we-be-more-optimistic

Prochaska, J. O., \& Velicer, W. F. (1997). The Transtheoretical Model of Health Behavior Change. American Journal of Health Promotion, 12(1), 38-48.

Progress in Reducing SIDS. (2013, September 23). Progress in Reducing SIDS. Retrieved from http://www.nichd.nih.gov/sts/about/SIDS/Pages/progress.aspx

Safe to Sleep ${ }^{\circledR}$ Public Education Campaign. (2013, December 19). Safe to Sleep ${ }^{\circledR}$ Public Education Campaign. Retrieved from http://www.nichd.nih.gov/sts/Pages/default.aspx

Schnitzer, P., Covington, T., \& Dykstra, H. (2012). Sudden Unexpected Infant Deaths: Sleep

Environment and Circumstances. American Journal of Public Health, 102(6), 1204-1212.

Sudden Infant Death Syndrome (SIDS) (2013, Oct 25). Centers for Disease Control and Prevention.

Retrieved from http://www.cdc.gov/features/sidsawarenessmonth/

Sudden Infant Death Syndrome: MedlinePlus. (2013, November 14). U.S National Library of Medicine.

Retrieved March 20, 2014, from

http://www.nlm.nih.gov/medlineplus/suddeninfantdeathsyndrome.html

Sudden Unexpected Infant Death (SUID). (2014, February 11). Centers for Disease Control and

Prevention. Retrieved March 20, 2014, from http://www.cdc.gov/sids/index.htm

Transtheoretical model. (2014, March 30). Wikipedia. Retrieved April 3, 2014, from 
http://en.wikipedia.org/wiki/Transtheoretical_model

Weber, M., Risdon, R., Ashworth, M., Malone, M., \& Sebire, N. (2012). Autopsy findings of co-sleepingassociated sudden unexpected deaths in infancy: Relationship between pathological features and asphyxial mode of death. Journal of Pediatrics \& Child Health, 48(4), 335-341. doi:10.1111/j.14401754.2011.02228.x

Yingling, F., Stombaugh, H., Jeffrey, J., LaPorte, F., \& Oswanski, M. (2011). Pediatricians' knowledge, perceptions, and behaviors regarding car booster seats. Journal Of Community Health, 36(1), 166173. doi:10.1007/s10900-010-9294-x

Yikilkan, H., Ünalan, P., Cakir, E., Ersu, R., Cifcili, S., Akman, M., \& ... Dagli, E. (2011). Sudden infant death syndrome: How much mothers and health professionals know. Pediatrics International, 53(1), 24-28. doi:10.1111/j.1442-200X.2010.03202.x 